\title{
EDUCAÇÃO AMBIENTAL E LEGISLAÇÃO: REFLEXÕES SOBRE PARTICIPAÇÃO E EFETIVIDADE
}

\author{
Lígia Viana Azevedo ${ }^{1}$ \\ Simone Alves Alexandrino² \\ Joyce Luana Marciano da Silva ${ }^{3}$ \\ Daniela Rocha Teixeira Riondet Costa ${ }^{4}$
}

Resumo: $O$ presente artigo objetiva, por meio de um aprofundamento na literatura e normas, destacar o arcabouço legal sobre a Educação Ambiental no Brasil, em especial a Lei o․ 9.795/99, que institui a Política Nacional de Educação Ambiental - PNEA. Buscou-se com este estudo demonstrar como as normas podem servir de importante ferramenta para orientação e fomento do despertar da consciência ecológica nos indivíduos. Mediante a pesquisa bibliográfica e documental, procurou-se ofertar, assim, uma semente de reflexão acerca da participação social e a esfera da efetividade das Leis. No que se refere à abordagem do problema, trabalhou-se com a coleta de dados através de leituras e análise, tornando-se a pesquisa qualitativa.

Palavras-chave: Educação Ambiental; Legislação; Política Nacional de Educação Ambiental; Consciência Ecológica.

1 Universidade Federal de Itajubá. E-mail: ligia.viana.azevedo@gmail.com

2 Universidade Federal de Itajubá. E-mail: simonealexandrino.adv@gmail.com

3 Universidade Federal de Itajubá. E-mail: jluana@gmail.com

${ }^{4}$ Universidade Federal de Itajubá. E-mail: daniela.unifei@gmail.com

Revbea, São Paulo, V. 12, № 2: 284-295, 2017. 


\section{Introdução}

É evidente que o planeta encontra-se mergulhado em uma profunda crise ambiental. Conforme aponta Boff (1999, p.20), há um descuido e um descaso em sua preservação, e assevera que "não dá mais para nos iludir, cobrindo as feridas da Terra com esparadrapos. Ou mudamos de curso, preservando as condições de vitalidade da Terra ou o abismo já nos espera".

Assim, forçoso reconhecer que a crise ambiental que hoje se apresenta é consequência do modelo civilizatório da modernidade, em que, segundo Machado (2014, p.34), a natureza é incorporada ao trabalho, já não é mais um obstáculo, ao contrário, é um recurso a ser controlado e explorado. No que concerne ao desenvolvimento, seguindo as lições de Sen (2000, p.17), este deve ser compreendido muito além do PIB e dos avanços materiais que se apresentam. Certo é que o meio ambiente sofre porque se interpreta equivocadamente que desenvolvimento significa somente avanço tecnológico e industrialização, em uma competição desenfreada e consumista.

A partir destas considerações, vislumbra-se na Educação Ambiental (EA) uma ferramenta estratégica para se mudar o rumo da história e sensibilizar os indivíduos na direção de uma consciência ecológica.

Portanto, objetivando contribuir com conhecimentos sobre o tema e a problemática deste cenário é que se redige este artigo, buscando destacar as legislações pátrias sobre a EA, por meio de pesquisa bibliográfica e documental, bem como propiciar uma reflexão quanto à esfera da efetividade das Leis por meio da participação social. No que se refere à abordagem do problema, esta se demonstra mediante a coleta de dados através de leituras e análise, tornando-se a pesquisa qualitativa.

\section{Educação Ambiental: Legislação Brasileira}

No que concerne à temática Legislação, embora não seja um documento brasileiro, imperioso desde já destacar que a Declaração Universal dos Direitos Humanos de 1948 preceitua que "Toda a pessoa tem direito a um nível de vida suficiente para the assegurar e à sua família a saúde e o bem-estar".

Neste sentido, A Declaração das Nações Unidas sobre o Meio Ambiente Humano, firmada em Estocolmo, Suécia, em 1972, em seu Princípio 1ํㅡ, também preconiza que

o homem tem um direito fundamental à liberdade, à igualdade e a condições de vida satisfatórias, num ambiente cuja qualidade lhe permita viver com dignidade e bem-estar. Ele tem o dever solene de proteger e melhorar o meio ambiente para as gerações presentes e futuras. 
Sobreditos princípios foram adotados pela Constituição Federal de 1988. Seguindo Kelsen (1987, p.240), autor da Teoria Pura do Direito - em que há uma pirâmide e o seu topo é ocupado pela Constituição, que dá validade a todas as outras Leis que com ela estiverem em consonância - a atual Lei Maior reservou capítulo específico sobre o meio ambiente, não se olvidando ainda de determinar explicitamente no inciso VI do $\S 1^{\circ}$ do artigo 225 do Capítulo VI, que o Poder Público tem a incumbência de promover a EA em todos os níveis de ensino e a conscientização pública para a preservação do ambiente.

Cabe ressaltar que o mandamento constitucional em apreço fora precedido pela Lei ㄲo. 6.938/1981, que instituiu a Política Nacional do Meio Ambiente, já anunciando em seu artigo $2^{\circ}$, inciso $X$, que a EA deveria atingir todos os níveis de ensino, inclusive a educação da comunidade, objetivando capacitá-la para participação ativa na defesa do ambiente.

Nesta esteira, insta informar que sobredita Lei fora também precedida pela Lei $n^{\circ}$. 5.197/1967, que dispõe sobre a proteção à fauna. Determina o seu art. 35 que dentro de dois anos a partir de sua promulgação, nenhuma Autoridade poderá permitir a adoção de livros escolares de leitura que não contenham textos sobre a proteção da fauna, aprovados pelo Conselho Federal de Educação. Ademais, o $\S 1^{\circ}$ do artigo em comento preceitua que os Programas de ensino de nível primário e médio deverão contar pelo menos com duas aulas anuais sobre a matéria a que se refere o artigo.

Posteriormente, destaca-se, em especial, a Lei ㄲo. 9.795/99, regulamentada pelo Decreto ํ․ 4.281/02, que dispõe especificamente sobre a Educação Ambiental e institui a Política Nacional de Educação Ambiental (PNEA). Esta Lei preceitua que a EA é um componente essencial e permanente da educação nacional, devendo estar presente, de forma articulada, em todos os níveis e modalidades do processo educativo, em caráter formal e não formal.

Certo é que além de definir a EA como o processo por meio do qual o indivíduo e a coletividade constroem valores sociais, conhecimentos, habilidades, atitudes e competências voltadas para a conservação do ambiente, esta Lei também enuncia princípios básicos e aponta objetivos fundamentais da EA.

Destarte, vale aqui destacar o seu art. $4^{\circ}$, em que são arrolados os seguintes princípios básicos da EA:

I - o enfoque humanista, holístico, democrático e participativo;

II - a concepção do meio ambiente em sua totalidade, considerando a interdependência entre o meio natural, o socioeconômico e 0 cultural, sob 0 enfoque da sustentabilidade;

III - o pluralismo de ideias e concepções pedagógicas, na perspectiva da inter, multi e transdisciplinaridade; 
IV - a vinculação entre a ética, a educação, o trabalho e as práticas sociais;

$\mathrm{V}$ - a garantia de continuidade e permanência do processo educativo;

VI - a permanente avaliação crítica do processo educativo;

VII - a abordagem articulada das questões ambientais locais, regionais, nacionais e globais;

VIII - o reconhecimento e o respeito à pluralidade e à diversidade individual e cultural.

Para Adams (2012, p.2153), observando cada um dos princípios delimitados como norteadores das práticas de EA, podem-se destacar alguns conceitos chave como: totalidade, interdependência, pluralismo, ética, articulação, perspectiva crítica, respeito, direitos, multiculturalidade, plurietnicidade e cidadania planetária, conceitos estes que devem ser bem compreendidos pela sociedade para que seja possível alcançar os objetivos da EA.

Nesta esteira, em sintonia com os princípios supra, têm-se os seus objetivos fundamentais, insculpidos no art. $5^{\circ}$, nos seguintes termos:

I - o desenvolvimento de uma compreensão integrada do meio ambiente em suas múltiplas e complexas relações, envolvendo aspectos ecológicos, psicológicos, legais, políticos, sociais, econômicos, científicos, culturais e éticos;

II - a garantia de democratização das informações ambientais;

III - o estímulo e o fortalecimento de uma consciência crítica sobre a problemática ambiental e social;

IV - o incentivo à participação individual e coletiva, permanente e responsável, na preservação do equilíbrio do meio ambiente, entendendo-se a defesa da qualidade ambiental como um valor inseparável do exercício da cidadania;

V - o estímulo à cooperação entre as diversas regiões do País, em níveis micro e macrorregionais, com vistas à construção de uma sociedade ambientalmente equilibrada, fundada nos princípios da liberdade, igualdade, solidariedade, democracia, justiça social, responsabilidade e sustentabilidade;

VI - o fomento e o fortalecimento da integração com a ciência e a tecnologia;

VII - o fortalecimento da cidadania, autodeterminação dos povos e solidariedade como fundamentos para o futuro da humanidade. 
Novamente, corrobora para o assunto Adams (2012, p.2154), ao destacar que os objetivos apresentados são amplos, abrangentes e remetem a uma educação voltada para o desenvolvimento do senso crítico em relação ao ambiente, relacionando aspectos socioambientais e cidadania, evidenciando, assim, o caráter democrático que deve estar presente nas práticas de EA.

Assim, ao analisar com cuidado os princípios e objetivos da Lei 9.795/99, verifica-se de forma inquestionável o seu caráter participativo, pois as suas diretrizes conclamam o envolvimento de todos, especialmente da escola, espaço profícuo para o seu efetivo progresso, onde se está constantemente formando personalidades e cidadãos.

Consoante às ponderações de Minc (2005, p.71),

as escolas devem funcionar como polos irradiadores de consciência ecológica, envolvendo as famílias e a comunidade. Escolas podem defender lagos, reflorestar encostas, abrigar centros de reciclagem.

Neste contexto, também é possível extrair de Sorrentino et al. (2005, p.287), que a EA, em específico, ao educar para a cidadania, pode construir a possibilidade da ação política, no sentido de contribuir para formar uma coletividade que é responsável pelo mundo que habita.

Insta ressaltar, outrossim, que a PNEA fornece um roteiro para a prática da educação ambiental, constituindo-se verdadeira ferramenta para o despertar da consciência ecológica. Porém, segundo Santos (2000), as soluções esperadas só poderão ser conseguidas em havendo programas ambientais desenvolvidos com toda a seriedade e técnicas exigidas ao fim que se pretende.

Ainda, bem pondera Santos (2000), seguindo as diretrizes de David S.Wood e Diane Walton Wood no trabalho "Como Planificar un Programa de Educacion Ambiental", que para criar e desenvolver um programa de EA devese planejá-lo e executá-lo de forma mais criteriosa e concreta possível, observando as seguintes etapas, por exemplo: a) avaliação da realidade ambiental; b) identificação do público; c) identificação da mensagem; d) seleção de uma estratégica educativa e e) avaliação.

Ultrapassadas estas reflexões, porém ainda destacando o conteúdo da Lei 9.795/99, verifica-se em seu artigo 10 que a EA será desenvolvida como uma prática educativa integrada, contínua e permanente, não devendo se constituir disciplina específica no currículo de ensino, exceto nos cursos de pós-graduação e extensão e nas áreas voltadas ao aspecto metodológico da EA, quando necessário.

Em continuidade, o seu artigo 11 preceitua que a dimensão ambiental deve constar dos currículos de formação de professores, em todos os níveis e em todas as disciplinas.

Revbea, São Paulo, V. 12, № 2: 284-295, 2017. 
Assim, sobreditos comandos evidenciam o caráter transversal da EA, corroborando sobre o assunto Tavares (2013, p.83), nos seguintes termos:

A educação ambiental surge com a responsabilidade de provocar uma transformação da linearidade, disciplinaridade, dicotomia inerente das nossas práticas educativas e tem como desafio o rompimento com essa lógica. As discussões em âmbito nacional e internacional direcionam para que apenas por uma prática interdisciplinar, em que o meio ambiente seja entendido como um todo sem fronteiras, perpassando transversalmente todas as áreas do conhecimento, é que o objetivo da educação ambiental poderá ser vislumbrado.

Em adição, ainda sobre a transversalidade da EA, Mazzarino, Munhoz, Keil (2013, p.59) destacam que "é possível que sintamos a educação ambiental na pele, e não pelo intelecto apenas, libertando-nos num currículo rizomático, que proporcione novas ancoragens semióticas e transversas".

Ante todo o exposto, indiscutível, pois, a suma importância deste diploma legal, bem como as suas diretrizes participativas, vez que a participação social relativamente ao meio ambiente é salutar, desde que acompanhada da educação ambiental em toda a sua plenitude, pois um complementa o outro e tornam-se aptos, por conseguinte, a promover o verdadeiro desenvolvimento.

Uma vez evidenciada a relevância da Lei o․ 9.795/99 que institui a PNEA, outro diploma em que existe a preocupação com a EA é a Lei №. 9.985/2000, que regulamenta 0 art. 225, § 1으. incisos I, II, III e VII da Constituição Federal e institui o Sistema Nacional de Unidades de Conservação da Natureza - SNUC.

Verifica-se em sobredita Lei que o termo Educação relacionada ao meio ambiente aparece de forma constante em seu conteúdo, evidenciando, pois, a preocupação de se conservar a natureza mediante o contínuo esclarecimento e participação. Percebe-se a preocupação com a EA quando a lei aborda a visitação pública nas diferentes categorias de unidades de conservação. Notese que mesmo nos casos de estações ecológicas e reservas biológicas, em que a visitação pública é proibida, ainda assim será excepcionalmente permitida quando tenha objetivos educacionais.

Merece ser destacada, ainda, a Lei ㄲo. 11.284/2006, que dispõe sobre a gestão de florestas públicas para a produção sustentável, contendo em seu art. $41, \S 1^{\circ}$ que os recursos do Fundo Nacional de Desenvolvimento Florestal FNDF serão aplicados prioritariamente em projetos nas seguintes áreas: ... VII educação ambiental.

Neste conjunto, outra Lei que se evidencia é a Lei $n$ o. 11.516/2007, que trata da criação do ICMBio - Instituto Chico Mendes de Conservação da Biodiversidade, sendo necessário ressaltar a temática EA em seu conteúdo, nos seguintes termos:

revista brasileira educação ambiental 
Art. 1․ Fica criado o Instituto Chico Mendes de Conservação da Biodiversidade - Instituto Chico Mendes, autarquia federal dotada de personalidade jurídica de direito público, autonomia administrativa e financeira, vinculada ao Ministério do Meio Ambiente, com a finalidade de:

III - fomentar e executar programas de pesquisa, proteção, preservação e conservação da biodiversidade e de educação ambiental.

Imprescindível, ademais, tratar das Leis n‥ 12.305/2010, que institui a Política Nacional de Resíduos Sólidos articulada com a Política Nacional de Saneamento Básico (Lei no. 11.445/2007), que também reconhece a EA como um instrumento indispensável para a gestão integrada, a redução, a reutilização e a reciclagem de resíduos sólidos.

Antes de se finalizar a temática da legislação brasileira voltada à $E A$, torna-se também importante destacar a Lei no. 12.633/2012, que instituiu o Dia Nacional da EA, a ser comemorado, anualmente, no dia 3 de junho, em todo 0 território nacional.

Portanto, resta clara e inequívoca a riqueza da EA no ordenamento jurídico brasileiro, todavia embora diversas Leis e suas palavras coercitivas se apresentem com a específica finalidade de se proteger o meio ambiente, de suas mais diversas formas, forçoso é reconhecer de que nada valem se não concretizadas mediante atos de consciência ecológica e participação social, em um crescendo de respeito por tudo o que existe e o que possa vir a existir. Seguindo esta linha destaca-se Chiavenato (2005, p.7): "Não adianta chorar a árvore derrubada. Lágrimas não purificam o rio poluído. Dor ou raiva não ressuscitam os animais. Não há indignação que nos restitua o ar puro. É preciso ir à raiz do problema".

\section{Educação Ambiental: aspectos participativos nas normas brasileiras e considerações sobre a sua efetividade}

A legislação favorável à EA que vem se constituindo no Brasil, a exemplo das Leis citadas nos parágrafos precedentes, certamente possui vertente participativa, vez que a participação da coletividade na defesa do meio ambiente é ressaltada repetidas vezes nestes documentos.

Segundo Fiorillo (2008, p.53), "a Educação Ambiental é decorrente do princípio da participação, onde se busca trazer uma consciência ecológica à população, titular do direito ao meio ambiente".

Neste sentido, Morimoto (2014, p.287), ressalta que 
diversos foram os autores que defenderam uma relação estreita entre o aumento do acesso ao conhecimento e a motivação tanto para a mudança de atitudes individuais e coletivas, quanto para o envolvimento com causas socioambientais, incluindo aí, o incremento no engajamento e na participação em processos decisórios. Isto porque, o conhecimento pode abrir caminhos para a avaliação crítica da realidade e tal avaliação pode também evoluir para a busca por soluções para os problemas da coletividade.

Considerando sobreditos argumentos, é possível encontrar em Dallari (2004, p.33), "que todos têm o dever de participar da vida social, procurando exercer influência sobre as decisões de interesse comum".

Novamente, Morimoto (2014, p.55) contribui sobre a temática, ao analisar o termo participação, da seguinte forma:

O termo participação popular, de fato, apresenta uma associação mais direta com "tudo aquilo que diz respeito ao povo" (conforme a definição do verbete popular pelos principais dicionários). Assim, possibilita a inclusão dos mais variados sujeitos que devem ter acesso às instâncias participativas relacionadas à proteção ambiental no Brasil, afinal, os políticos, os funcionários públicos, os silvícolas, os letrados, os analfabetos, os menores de idade, os portadores de necessidades especiais, aqueles que ocupam espaços institucionalizados, os que atuam em instâncias informais, os que agem individualmente, os que se associam a grupos, e todos os demais habitantes do território nacional, podem e devem na medida de suas possibilidades, participar da definição dos rumos que sua vida, sua comunidade e seu país poderão tomar.

Assim, antes de se destacar os aspectos participativos contidos nas normas brasileiras de EA em estudo, vale a pena ressaltar que a participação efetiva conduz à concretização da cidadania e bem aponta Pereira, Ferreira (2008, p.17) que

o interesse pela questão ambiental está diretamente vinculado ao interesse pela realização integral do indivíduo como ser humano. O pouco caso com a questão ambiental denota o pouco caso com a qualidade de vida. Por isso, é tão importante que o cidadão seja hoje, ecocidadão.

Ultrapassadas estas considerações, passa-se a demonstrar a perspectiva participativa da EA partindo-se da Constituição Federal de 1988, vez que, segundo Costa (2012, p. 145), "a Constituição Federal é suprema, é o 
conjunto de normas que organiza os elementos que constituem o Estado, é a ordem máxima de um país". Esta Lei Maior traz no art. 225 o direito de todos ao meio ambiente ecologicamente equilibrado e essencial à sadia qualidade de vida, sendo obrigação do Poder Público e da Sociedade o dever de defendê-lo e preservá-lo para as presentes e futuras gerações.

Também a Lei no. 11.284/2006, que versa sobre a gestão de florestas públicas para a produção sustentável, possui viés participativo e busca efetivar a participação por meio dos conselhos. Verifica-se este viés no $\S 2^{\circ}$ do artigo 41 (BRASIL, 2006), onde O Fundo Nacional de Desenvolvimento Florestal FNDF contará com um conselho consultivo, com participação dos entes federativos e da sociedade civil.

Neste sentido, a Lei no. 9.985/2000, que institui o Sistema Nacional de Unidades de Conservação - SNUC, também preconiza em seus artigos as seguintes diretrizes participativas (BRASIL, 2000):

Art. 5․ O SNUC será regido por diretrizes que:

II - assegurem os mecanismos e procedimentos necessários ao envolvimento da sociedade no estabelecimento e na revisão da política nacional de unidades de conservação;

III - assegurem a participação efetiva das populações locais na criação, implantação e gestão das unidades de conservação. (grifo nosso)

Em especial, destaca-se o caráter participativo na Lei no. 9.795/1999 que dispõe sobre a EA e institui a PNEA. Esta lei traz como princípio básico da EA o enfoque humanista, holístico, democrático e participativo. Também, como objetivos fundamentais o incentivo à participação individual e coletiva; o estímulo à cooperação; sensibilização da coletividade; a ampla participação da escola, da universidade e de organizações não governamentais na formulação e execução de programas e a participação de empresas públicas e privadas no desenvolvimento de programas de educação ambiental em parceria com a escola. (BRASIL, 1999).

Ante todo o exposto, é oportuno também ponderar sobre a esfera da efetividade das Leis, pois conforme já destacado, verifica-se que a legislação nacional se apresenta sobremaneira vasta quanto à $E A$, aí inclusa a participação social, porém mais uma vez cabe a reflexão de que nada vale se não efetivada mediante atos concretos de respeito ao meio ambiente.

Em consonância ao afirmado acima, encontra-se em Benjamim (2003, p.365) que "por trás de toda a teoria da implementação está o desejo de ver a lei verdadeiramente aplicada, alcançando-se, assim, seus objetivos e finalidades, motivo de sua própria promulgação".

Nesta esteira, consoante as lições extraídas de Morimoto (2014, p.335), 
meio ambiente se maior for a dedicação por parte da sociedade em exigir que a Administração promova políticas públicas voltadas ao empoderamento da própria sociedade civil através da ampliação do acesso a conhecimentos essenciais à apropriação dos canais de participação em processos de tomada de decisões e de controle social.

Em adição, bem aponta Portella (2000, p.97) que a efetividade é deixada de lado pelas mais variadas razões, que vão desde a falta de uma cultura jurídica até a supremacia do interesse econômico, que se legitima e dita procedimentos em nome do direito de alguns poucos.

\section{Considerações finais}

A partir do estudo acima, delineado com o foco precípuo na Legislação nacional e a participação social, tornou-se possível concluir que o arcabouço legislativo sobre a matéria é sobremaneira vasto e avançado.

Ocorre que, a evolução pretendida pelas Leis e a consequente preservação do meio ambiente, somente não é completa devido ao campo da efetividade, vez que em todas elas encontram-se diversos dispositivos para a mais perfeita execução dos programas de Educação Ambiental.

Certo é que determinada Lei existe ou para ser cumprida ou para ser questionada, visando melhorias, merecendo ser rechaçada a ideia das famosas leis que "não pegam", pois não se trata de se estabelecer empatia com o seus conteúdos, porém de dar-lhes vida, buscando fomentar o respeito do homem pelo meio ambiente a sua volta e a compreensão de que é parte dele também, em uma constante evolução da participação social, visando à efetivação da Educação Ambiental.

\section{Referências}

ADAMS, B.G. A importância da Lei 9795/99 e das Diretrizes Curriculares Nacionais da Educação Ambiental para Docentes. Monografias Ambientais REMOA/UFSM. Cascavel, ㄲo 10: p. 2148-2157, out-dez/2012. Disponível em: $<$ http://cascavel.ufsm.br/revistas/ojs-

2.2.2/index.php/remoa/article/view/6926>. Acesso em 25/05/2015.

BOFF, L. Saber cuidar: ética do humano - compaixão pela terra. $11^{\mathrm{a}} \mathrm{ed}$. Petrópolis: Vozes, 1999.

BRASIL. Constituição da República Federativa do Brasil, de 05 de outubro de $1988 . \quad$ Disponível em: $<$ http://www.planalto.gov.br/ccivil 03/constituicao/constituicao.htm>. Acesso em 25/04/2015.

BRASIL. Lei no. 5.197 de 03 de janeiro de 1967. Disponível em: <http://www.planalto.gov.br/ccivil 03/leis/L5197.htm>. Acesso em: 04/05/2015. 
BRASIL. Lei no. 6.938 de 31 de agosto de 1981. Disponível em: $<$ http://www.planalto.gov.br/ccivil 03/leis/l6938.htm>. Acesso em: 03/05/2015.

BRASIL. Lei no. 9.795 de 27 de abril de 1999. Disponível em: $<$ http://www.planalto.gov.br/ccivil 03/leis/l9795.htm>. Acesso em: 25/02/2015.

BRASIL. Lei no. 9.985 de 18 de julho de 2000. Disponível em: $<$ http://www.planalto.gov.br/ccivil 03/leis/L9985.htm>. Acesso em: 04/06/2015.

BRASIL. Lei no. 11.284 de 02 de março de 2006. Disponível em: <http://www.planalto.gov.br/ccivil 03/ ato2004-2006/2006/lei/l11284.htm>.

Acesso em: 30/05/2015.

BRASIL. Lei no. 11.516 de 28 de agosto de 2007. Disponível em: $<$ http://www.planalto.gov.br/ccivil 03/ ato2007-2010/2007/lei//11516.htm>.

Acesso em: 02/06/2015.

BRASIL. Lei no. 11.445 de 05 de janeiro 2007. Disponível em: <http://www.planalto.gov.br/ccivil 03/ ato2007-2010/2007/lei/l11445.htm>.

Acesso em: 02/06/2015.

BRASIL. Lei no. 12.305 de 02 de agosto de 2010. Disponível em: <http://www.planalto.gov.br/ccivil 03/ ato2007-2010/2010/lei/l12305.htm>.

Acesso em: 03/06/2015.

BRASIL. Lei no. 12.633 de 14 de maio de 2012. Disponível em: <http://www.planalto.gov.br/ccivil 03/ Ato2011-2014/2012/Lei/L12633.htm>.

Acesso em 05/06/2015.

CHIAVENATO, J.J. 0 Massacre da natureza. $2^{\underline{a}}$ ed. São Paulo: Moderna, 2005.

DALLARI, D.A. O Que é Participação Política? São Paulo: Brasiliense, 2004.

DECLARAÇÃO DAS NAÇÕES UNIDAS SOBRE O MEIO AMBIENTE HUMANO. Disponível na Biblioteca Virtual de Direitos Humanos da Universidade de São Paulo: www.direitoshumanos.usp.br. Acesso em 25/04/2015.

DECLARAÇÃO UNIVERSAL DOS DIREITOS HUMANOS. Disponível na Biblioteca Virtual de Direitos Humanos da Universidade de São Paulo: www.direitoshumanos.usp.br. Acesso em 25/04/2015.

FIORILLO, C.A.P. Curso de Direito Ambiental Brasileiro. 9a ed. São Paulo: Saraiva, 2008.

KELSEN, H. Teoria Pura do Direito. São Paulo: Martins Fontes, 1987.

MACHADO, J.T. Educação ambiental: um estudo sobre a ambientalização do cotidiano escolar. 2014. 245f. Tese (Doutorado em ciências). Programa de Pós-Graduação da Escola Superior de Agricultura "Luiz de Queiroz" - USP. Piracicaba, 2014. 
MAZZARINO, J.M.; MUNHOZ, A.V.; KEIL, J.L. Currículo, Transversalidade e Sentidos em Educação Ambiental. Revbea. Rio Grande, V. 7, No 2: 51-61, 2012.

MINC, C. Ecologia e cidadania. 2ª ed. São Paulo: Moderna, 2005.

MORIMOTO, I.A. Direito e educação ambiental: estímulo à participação crítica e à efetiva aplicação de normas voltadas à proteção ambiental no Brasil. 2014. 501f. Tese (Doutorado em ciência ambiental). Programa de Pós-Graduação em Ciência Ambiental (PROCAM) da Universidade de São Paulo. São Paulo, 2014.

PEREIRA, D.; FERREIRA, R. Ecocidadão. Secretaria do Meio Ambiente do Estado de São Paulo. São Paulo: SMA/CEA, 2008.

PORTELLA, C.A. A ineficácia das normas constitucionais ambientais. Revista Direito em Debate. 2000. v. 9, n. 14 . p. 97-117.

SANTOS, A.S.R. Educação Ambiental e o Poder Público. Disponível em: $<$ http://www.aultimaarcadenoe.com.br/educacao-ambiental/> $>$. Acesso em $26 / 05 / 15$.

SEN, A.K. Desenvolvimento como liberdade. São Paulo: Companhia das Letras, 2000.

SORRENTINO, M.; TRAJBER, R.; MENDONÇA, P.; FERRARO JÚNIOR, L.A. Educação ambiental como política pública. Educação e Pesquisa. São Paulo, V. 31, n. 2, p. 285-299, maio-ago/2005.

TAVARES, G.S. O que pensam os professores sobre a criação de uma disciplina de Educação Ambiental? Revbea. Rio Grande, V. 8, No 1, p.83-90, 2013. 